\title{
PROCESSING OF OIL WELL PRESSURE RECOVERY CURVES
}

\author{
Abasova Inara Afrail, \\ Azerbaijan, Baku, \\ Azerbaijan State Oil and Industry University, department "Computer Engineering", assistant.
}

DOI: https://doi.org/10.31435/rssglobal_sr/31012019/6336

\section{ARTICLE INFO}

Received 08 November 2018

Accepted 19 January 2019

Published 31 January 2019

\section{KEYWORDS}

well reservoir,

PRC,

indicator curves, permeability, hydro-conductivity, piezo-conductivity, well productivity.

\begin{abstract}
In the article the development of a mathematical model describing the PRC is studied on the base of pressure recovery curve method.

Detailed processing of the pressure recovery curve made it possible to determine the deterioration of reservoir permeability in many wells. Here two methods are considered - stationary (steady conditions of selection) and nonstationary.

The article proves that the use of these methods allows to develop a mathematical model to increase the determination of this task.

On the base of numerical simulation, the following facts had impact on the results of the pressure recovery curve: well shutdown time, taking into account the initial transition section, taking into account curve change section before well shutdown.

The study of variable factors impact on the results is carried out by interval estimation.

The mathematical model describing the pressure recovery curve is local and changes its structures. This model can be used in industry conditions.
\end{abstract}

Citation: Abasova Inara Afrail. (2019) Processing of Oil Well Pressure Recovery Curves. Science Review. 1(18). doi: 10.31435/rsglobal_sr/31012019/6336

Copyright: (C) 2019 Abasova Inara Afrail. This is an open-access article distributed under the terms of the Creative Commons Attribution License (CC BY). The use, distribution or reproduction in other forums is permitted, provided the original author(s) or licensor are credited and that the original publication in this journal is cited, in accordance with accepted academic practice. No use, distribution or reproduction is permitted which does not comply with these terms.

Introduction. As it is known, two methods are used for hydrodynamic studies of oil wells and reservoirs - stationary (steady selection conditions) $(1,2)$ and non-stationary.

In the stationary method, at some steady conditions of the studied oil well operation, bottomhole pressure and yield are measured, leaving the well to be operated in this condition for several hours (from 12 hours to 24 hours). After that, a new mode of operation is constructed and again the above mentioned parameters are measured. Four-five points of the yield are taken off in case of curves being dependent on bottom-hole pressure curve and the indicator curves are constructed [1,2]. The indicator curves determine the coefficients of well productivity, permeability, hydro- piezoconductivity of the reservoir.

In the non-stationary method (at unsteady well operation condition) or the method of restoring (falling) the bottom-hole pressure (BP) to the reservoir [2,3-7], the essence of the study consists in the speed of the BP recovery when the well stops or the rate of BP decreases after setting wells in operation [3].

There are various methods of processing experimental pressure recovery curves (PRC) to determine the characteristics of the oil reservoir and wells $[4,6]$, where for the mathematical description of PRC using a third-degree polynomial, the left side of the PRC is described by a seconddegree polynomial [4].

Statement of the problem. The above-stated problems imply the need to develop a mathematical model that adequately describes the PRC. And the proposed article is dedicated to solving this problem. 
The solution of the problem. As it is known, the measurement of BP (after closing wells) is an aperiodic (inertial) circuit, which is described by a differential equation of the first order of the form:

$$
T \frac{d(\Delta P)}{d t}+\Delta p=K_{y} A
$$

Using the Laplace transformation from equation (1), we obtain the following:

$$
(T S+1) \Delta P=K_{y} A,
$$

where $T$ is the constant time of the circuit; $S$ is the Laplace operator; $\Delta P$ the measurement of BP; $K_{y}$ is the gain factor, when $t \rightarrow \infty$ is equal to $\Delta p(\infty) / A ; A=\Delta Q=Q_{T} \quad Q_{0}$ - uneven decrease in the yield of the reservoir fluid from the current value $\left(Q_{T}\right)$ to zero $\left(Q_{0}\right)$.

The characteristic equation of expression (2) has the following form:

$$
Q(S)=T S+1=0, \text { therefore } Q(S)=T ; S=\frac{1}{T} .
$$

For an equation of the form (2) of the $\mathrm{n}^{\text {th }}$ order, when the input quantity is an uneven function:

$$
\Delta x=\Delta Q=\left\{\begin{array}{l}
A \text { if } t<0 \\
0 \text { if } t>0
\end{array}\right.
$$

The original (inverse Laplace transformation) is found from the equation.

Taking into account (3) and (4), the solution of the equation (2) is as follows

$$
\Delta P=K_{y} A\left(1-e^{-\frac{\tau}{T}}\right) .
$$

As it is seen from the obtained formula (5), the theoretical time of the transition process or the restoration of $\mathrm{BP}$ to the reservoir is equal to $\infty$, which is not practicable (for technical-economic reasons). Practically, we can assume that the transient process ends in the time during which the deviation $\Delta P$ reaches $95 \%$ of the maximum deviation corresponding to the new state of the circuit.

This time in the theory of automatic regulation, usually equals to $4 T$, is called the acceleration time. Moreover, in order to determine the value of $T$ from the starting point, (see fig.1) a graft is tangential until it crosses the line corresponding to the new steady-state value of BP (point a). Then the projection of the tangent segment on the time axis will be the value of $T$. In this case, the time of the transient process with a probability of 0.95 will be defined as $4 T$.

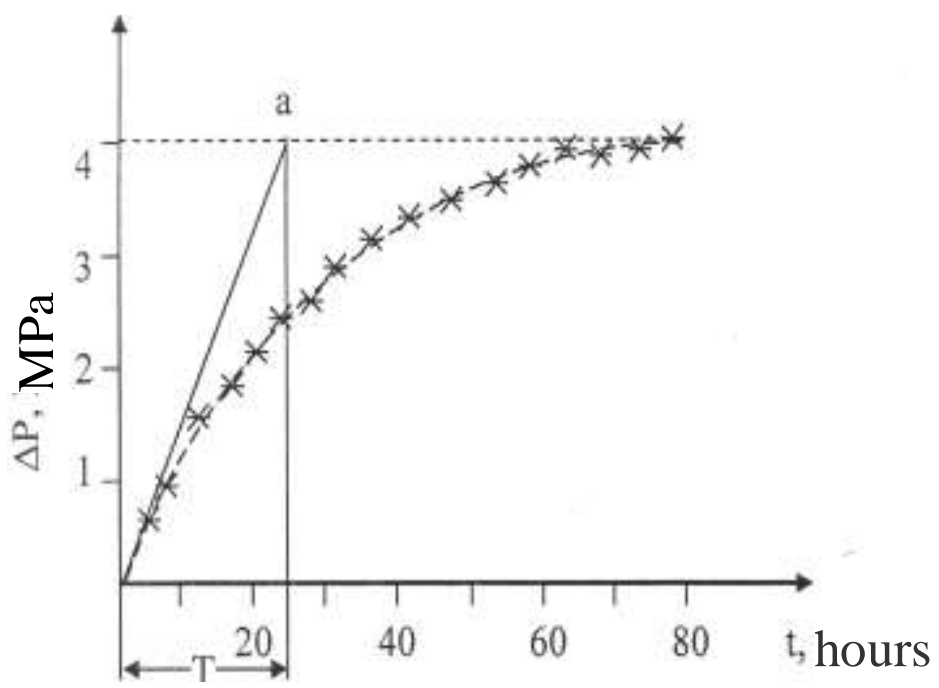

Fig. 1. Pressure recovery curve (PRC): on the base of experimental data; according to model (5) 
It should be noted that the available mathematical models [4], describing the PRC, have second and third degree polynomials. However, studies carried out have shown that, in this case the polynomials are the results of decomposition of expression (5) in a Taylor series. Therefore, they cannot be more adequately than the formula (5) describes the experimental data characterizing the PRC. In addition, the mathematical models obtained in [4] are local in nature and change their structures when transforming from one experimental data collected from one well to another experimental data collected from another well.

Thus, the proposed mathematical model, as it is seen from the figure, 5\% error adequately describes the experimental data on PRC and is invariant when transforming from one well to another, therefore, it is global and can be used in field conditions to interpret real PRC.

\section{REFERENCES}

1. Ivanov V.A, Solovev V.Y. Hydrodynamic studies of water bearing oil wells in steady selection conditions//Oil industry, 2010, N1, p.73-75.

2. Mirzanjanzade A.K, Khasanov M.M., Bakhtizin R.N. Modeling oil and gas production processes, 2004, $368 \mathrm{p}$.

3. Muravev V.M. Oil and gas well exploitation. M. Nedra, 1978.

4. Ponomarev I.N. The processing of pressure recovery curves of low producing wells//Oil industry, 2010, N6, p.78-79.

5. Ponomarev I.N., Savchik M.B. Erofeev A.A Conditions for the use of the skin factor for estimating the state of the near-wellbore zones of productive reservoirs//Oil industry, 2011, N7, p. 114-115.

6. Ponomarev I.N., Savchik M.B, Mordvinov V.A. Estimation of the duration of formation of pressure recovery curves in studies of producing wells//Oil industry, 2011, N7, p.112-113.

7. Shagiev R.G. The study of the well according to PRC. M. Science. 1998. 304.p. 